\title{
Spatiotemporal variability of vegetation phenology with reference to altitude and climate in the subtropical mountain and hill region, China
}

\author{
QIU BingWen ${ }^{1 *}$, ZHONG Ming ${ }^{1}$, TANG ZhengHong ${ }^{2}$ \& CHEN ChongCheng ${ }^{1}$ \\ ${ }^{1}$ Key Laboratory of Spatial Data Mining \& Information Sharing of Ministry of Education, Spatial Information Research Centre of Fujian \\ Province, Fuzhou University, Fuzhou 350002, China; \\ ${ }^{2}$ Community and Regional Planning Program, University of Nebraska-Lincoln, Lincoln 68588, USA
}

Received September 4, 2012; accepted January 30, 2013; published online May 15, 2013

\begin{abstract}
Understanding the seasonal behaviour of a subtropical forest and its inter-annual variation is crucial to understanding and monitoring its ecosystem function in the context of global warming. Based on the Moderate Resolution Imaging Spectroradiometer (MODIS) Enhanced Vegetation Index dataset, a wavelet transform method was used to investigate the inter-annual variations of vegetation phenology in a subtropical mountain and hill region in Fujian, China, during 2001-2010. The results show a distinct inter-annual variation of vegetation phenology related to climate variability even if most areas presented non-significant trends. The start dates significantly advanced and end dates delayed in 2003 and 2008, due to anomalously warm conditions. There was generally a gradient of increasing start dates, and earlier end dates of vegetation growing season, due to colder temperatures at higher altitudes. However, the altitudinal phenology relationship also depends on its corresponding rainfall conditions. Earlier start dates were observed at higher altitudes during rainfall deficit years such as 2008 , which coincides with relatively abundant rainfall at higher altitudes. This paper reveals that vegetation phenology was coupled with altitudinal gradient, with distinct responses at different combinations of alternate temperature and precipitation conditions variability.
\end{abstract}

vegetation phenology, climate change, Enhanced Vegetation Index (EVI), subtropical mountain and hill region, altitude gradient

Citation: Qiu B W, Zhong M, Tang Z H, et al. Spatiotemporal variability of vegetation phenology with reference to altitude and climate in the subtropical mountain and hill region, China. Chin Sci Bull, 2013, 58: 2883-2892, doi: 10.1007/s11434-013-5847-6

The subtropical forest region is usually represented as a homogeneous green area on the world maps. In reality, the subtropical forest in mountainous and hilly region is a heterogeneous continuum, with variations in local climate, altitude, water conditions and increasing anthropogenic influence. Research on phenology could be dated back to several decades [1,2]. Recently, numerous studies have revealed the changes in plant phenology and its connection with climate change through temporal monitoring of remotely sensed vegetation indices from local to global scales [3-6]. These studies have improved our knowledge of what constitutes significant change in land surface phenology

*Corresponding author (email: qiubingwen@fzu.edu.cn) amidst background variation. However, there are at least two important issues that need to be further investigated.

The first issue is the in-depth exploration of a relatively longer inter-annual variation of phenology based on medium or high resolution imagery in subtropical mountain and hill region. A relatively long investigation of vegetation phenology has been conducted with ground-based observation records and coarse spatial resolution imagery such as the GIMMS database [5,7-9]. Till now, only a few studies on vegetation phenology have been carried out based on a ten-year time series database of moderate resolution imagery such as MODIS [4], with even less research conducted on subtropical mountain and hill region.

The other issue is the detailed survey of all possible 
forcing mechanisms of vegetation phenology, especially the complex influence of climate change and altitudinal gradient. Several studies have revealed the connection between vegetation phenology cycles and climate changes, land cover and altitude [9-12]. For example, Jeganathan et al. [13] observed a general trend of earlier onset of greenness at low altitudes than at higher altitudes for natural vegetation in India. However, Chang et al. [14] documented a delayed onset of vegetation growth at lower altitudes in a tropical and subtropical region, Taiwan, using the MODIS NDVI dataset. Little research has been performed on the relationship between phenology and precipitation in the 20th century [15], although there is a growing interest in this field during the past few years [16-18]. Several studies have indicated substantial complexity in precipitation-phenological relationships. For example, Jenerette et al. [19] revealed that vegetation patterns were clearly coupled to precipitation variability, with distinct responses at alternative spatial and temporal scales. Ivits et al. [12] found that shorter season trends of vegetation growth over the Lake Tuz lowlands in Turkey were connected with decreasing precipitation. Lloyd et al. [20] suggest that the role of precipitation on vegetation growth changes along the latitudinal gradient, based on tree ring data and climate data from 1902 to 2002. Considering the complex and combined influence of temperature, precipitation and elevation, the mechanisms governing vegetation phenology in mountain and hill region are not well understood.

The aim of this paper is to assess the magnitude of vegetation phenology variability indicated by the beginning, end and length of the growing season, and their complex relation with climate change and topography in mountainous and hilly region, Fujian, China, based on the spatiotemporal variation of the $250 \mathrm{~m}$ Moderate Resolution Imaging Spectroradiometer (MODIS) Enhanced Vegetation Index (EVI) time series datasets from 2001 to 2010.

\section{Materials and methods}

\subsection{Study area}

Fujian Province is located between latitude $23^{\circ} 32^{\prime}-28^{\circ} 19^{\prime} \mathrm{N}$ and longitude $115^{\circ} 50^{\prime}-120^{\circ} 43^{\prime} \mathrm{E}$, southeast of China (Figure 1). It is approximately $530 \mathrm{~km}$ long; the widest part is approximately $480 \mathrm{~km}^{2}$ and the total land area is $121400 \mathrm{~km}^{2}$. The annual mean temperature fluctuates between 17 and $21^{\circ} \mathrm{C}$ and the yearly precipitation varies between $920-2100$ $\mathrm{mm}$ [21]. The mean elevation of Fujian is $475 \mathrm{~m}$ a.s.l. and the mean slope is around $15^{\circ}$. It has a very diverse relief with elevations from zero in the coastal area in the east to $2258 \mathrm{~m}$ in the northwest. Across this gradient, land cover varies from paddy fields near coastal areas to evergreen hardwood forest, mixed forests and conifer forests and meadows. The ratio of mountains, hills and plains is $15: 3: 2$ by using the threshold elevation of $500 \mathrm{~m}$ in distinguishing mountains and hills, and the threshold elevation of $50 \mathrm{~m}$ in distinguishing hills and plains [21]. Forests cover $68.7 \%$ of the land area. Coniferous forest, hardwood forest, and bamboo forest represent $66.8 \%, 32.2 \%$ and $13.5 \%$ of the forested area respectively [22]. Cultivated lands cover $10.82 \%$ of the land area. Urban areas cover $4.47 \%$ of the land area and are mostly located below $80 \mathrm{~m}$ elevation [23]. The subtropical forest in Fujian Province ranks first in China in terms of proportion of vegetation cover.

\subsection{Data source}

This study used a 16-d time series of $250 \mathrm{~m}$ MODIS surface reflectance data (MOD09Q1), acquired from 2001 to 2010. The MODIS land data products incorporate enhanced atmospheric correction, cloud detection, improved geo-referencing and enhanced ability to monitor vegetation [24]. The Enhanced Vegetation Index (EVI) product of MODIS is designed to provide consistent spatial and temporal comparisons
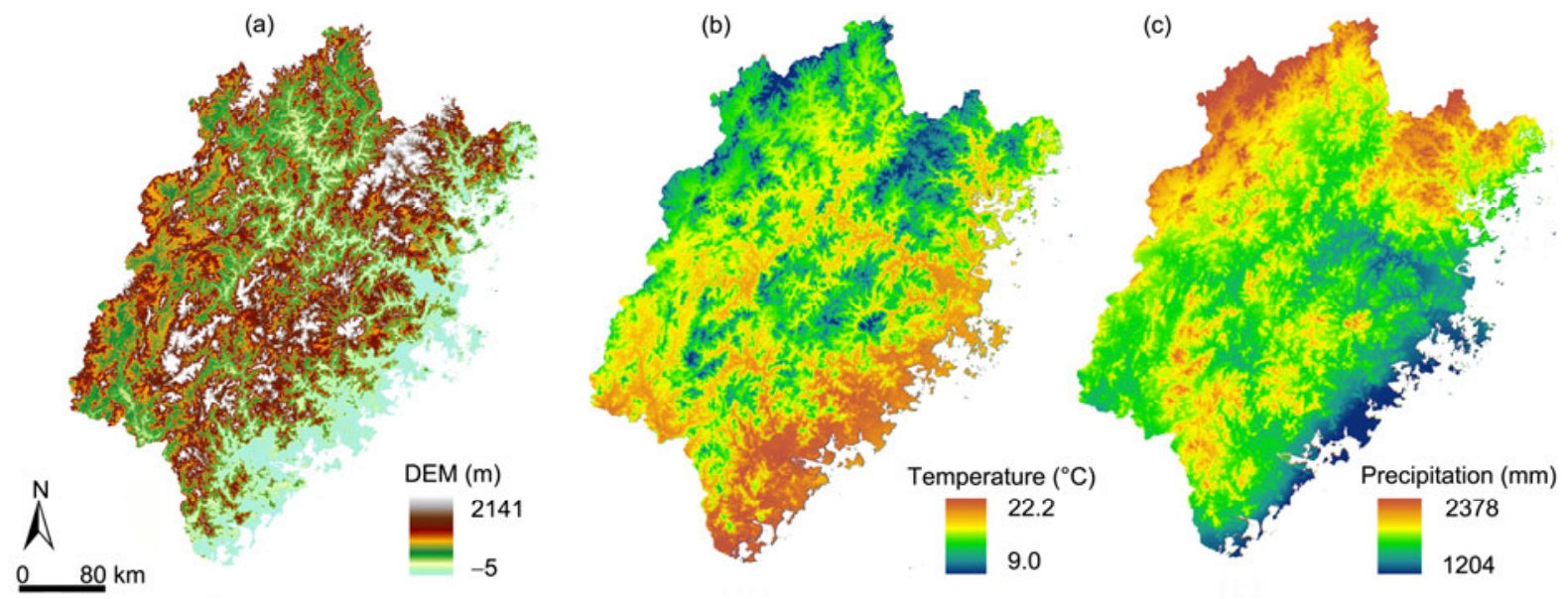

Figure 1 (Color online) Spatial distribution of topography (a), average annual temperature (b), and average annual precipitation (c) of Fujian Province during 2001-2010. 
of global vegetation conditions in finer detail than the NDVI product of NOAA AVHRR [24]. EVI produces a vegetation signal with improved sensitivity in high biomass regions and with improved vegetation monitoring through the reduction of soil and atmospheric influences [25]. The map projection was converted to Universal Transverse Mercator using ENVI image processing software.

Climate variables used are temperature and precipitation. Meteorological data were obtained from 67 stations from the Meteorological Information Centre of Fujian Province, China. Co-kriging interpolation was used to establish spatial distribution of monthly total precipitation and monthly average temperature (Figure 1). Topographic effect is critical for temperature and precipitation. The variables of longitude, latitude, and elevation are utilized to construct a linear function for precipitation; for function of mean, maximum and minimum temperature, the variables of aspect and slope are also included. The Co-kriging interpolation was implemented through programming with ArcObjects.

The DEM dataset utilized is the ASTER_GDEM dataset with a spatial resolution of $30 \mathrm{~m}$. We resampled the DEM dataset to $250 \mathrm{~m}$ in accordance with MODIS EVI images (Figure 1). The other data set used for this study consists of spatial explicit land use data and forest type data. The 1: 50000 land use distribution map and forest cover data were obtained from the Fujian Geological Surveying and the Fujian Forest Bureau, respectively. Database processing was conducted using ESRI software ARCGIS and ENVI software.

\subsection{Phenology determination}

Sakamoto et al. [26] proposed the Wavelet-based Filter for determining Crop Phenology to remove high-frequency noise in crop phenology data. The Wavelet-based Filter has been applied for determining Crop Phenology [27] or EVI time series smoothing [28] in other studies. They have demonstrated the stability of the wavelet approach to filter out noises in EVI time-series data and also gave the best time profile of EVI for the purpose of detecting phenology stages.

In this study, the wavelet transform is applied to a time series of MODIS EVI data in order to generate intra-annual vegetation pattern for exploring vegetation changes during 2001-2010. The Meyer orthogonal discrete wavelet has been applied and proved to be powerful in characterization of inter-annual and intra-annual vegetation variability [28-31]. The Meyer orthogonal discrete wavelet was chosen for this purpose [30]. Through wavelet transform, the original signal is continuously decomposed into a detail (D) and approximation (A) series at different levels. The detailed components from level 2 to level $5, \mathrm{D}_{2 \ldots . .5}$, which are ascribable to variations at scales of 24-48, 48-95, 95-190, and 190-380 d respectively, have been applied to examine the intra-annual vegetation dynamics. The sum of the detailed components up to level five can be considered as the total intra-annual variability, $V=\sum_{j=2}^{n} D_{j}$. The detailed component $D_{1}$ is excluded to reduce the high-frequency temporal noise [30].

White et al. [32] developed a formula to consistently catch the start and end of the growing season of vegetation, shown as

$$
\mathrm{EVI}_{\text {ratio }}=\left(\mathrm{EVI}-\mathrm{EVI}_{\text {min }}\right) /\left(\mathrm{EVI}_{\text {max }}-\mathrm{EVI}_{\text {min }}\right),
$$

where $\mathrm{EVI}_{\text {ratio }}$ is a ratio indicating the annual growth state, and EVI is the specified time EVI derived from V compo-

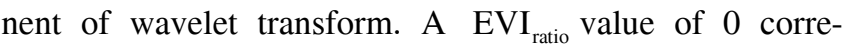
sponds to the annual minimum EVI; whereas a value of 1 corresponds to the annual maximum EVI and a value of 0.5 indicates 50 percent of maximum EVI attained. A particular threshold can be chosen to discriminate the start and end of the growing season. A EVI ratio value of 0.5 is widely used to identify the start and end of the growing season. It has been proved to be a stable and reliable approach to detect changes in vegetation states $[10,33]$.

\subsection{Statistical analysis}

The intra-annual variations of start dates, end dates and length of growing season during 2001-2010 were explored through a trend analysis based on the non-parametric Sen's method [34]. If the magnitude of total change is significantly different from zero, we may draw a conclusion that there exists a trend in the time data series. We also evaluate the inter-annual variations of temperature (average, maximum, minimum) and precipitation during the start dates (April for temperature, accumulated value of March and April for precipitation), and end dates (October for temperature, accumulated value of September and October for precipitation).

In addition, regression models are constructed to explore the relationship between elevation and each of the three phonological variables: start, end and length of the growing period. This study conducted related statistical tests for reliability of the regression models. There is no violation of regression assumptions regarding model specification, multicollinearity, heteroskedasticity, autocorrelation, influential data or outliers, or inter-item correlation issues.

\section{Results}

\subsection{Detecting phenological stages with EVI time profile}

Similar to the method proposed by Sakamoto et al. [26], we also defined the date of the maximum EVI in the time profile as the estimated heading date. The smoothed time profiles of EVI from both de-noised $A_{1}$ and intra-annual component $V$ are shown in Figure 2. These time profiles show the same seasonal tendency as the original EVI data. The changes 
around the planting season in the derivative of intra-component $V$ time profiles of the EVI is larger than those of denoised component $A_{1}$ time profile generated by wavelet transform. The dates of the minimal and inflection points differed slightly between time series profile of intra-annual component and de-noised component $A_{1}$. In addition, local changes in the intra-annual time series component were more obvious. We assumed that better characterization of EVI time component profile could lead to more accurate description of vegetation growing season. We believe that, both methods by using wavelet transform, the intra-annual component derived from multilevel decomposition are more sensitive to vegetation seasonal changes than the de-noised component.

\subsection{Spatial pattern of growing season phenology}

The spatial distribution of average start dates, end dates and the length of the growing season is shown in Figure 3. The start dates generally increase from south to north, reflecting spatial differences in climate and topography. Due to the relatively high altitude and low temperature in the northwest and northeast, the vegetation green-up there occurs in May. By contrast, the southwest has earlier green-up dates, usu- ally in April. The histogram of start dates over the Fujian Province indicates that most areas have start dates between the end of April and late May (101-144 d) (Figure 4). Conversely, the end dates generally increase from west to east and from north to south, also reflecting the spatial differences in both climate and topography. The histogram of end dates over the Fujian Province indicates that most areas have end dates between late September and early December (271-318 d) (Figure 4). Similar to the end dates, the length of growing season increases from northwest to southeast. The histogram of the length of growing season reveals that most areas range between 139-209 d (Figure 4).

To investigate the influence of elevation on vegetation phenology, we calculate the mean values of average start dates in the following altitudinal bands: below 100, 100200, 200-300......above $1400 \mathrm{~m}$. On the whole, a steady delayed start dates, earlier end dates and increased lengths of growing season are observed with increasing altitude. The start dates of growing season were delayed around $1.4 \mathrm{~d}$ with altitudinal increase of $100 \mathrm{~m}$. The relationship between start dates of growing season and elevation is shown in eq. (2) $\left(R^{2}=0.1063\right)$ and Figure 5. The model fitness was fairly low due to the considerably delayed start dates within altitudinal belt of 200-300 m and relatively earlier start dates within

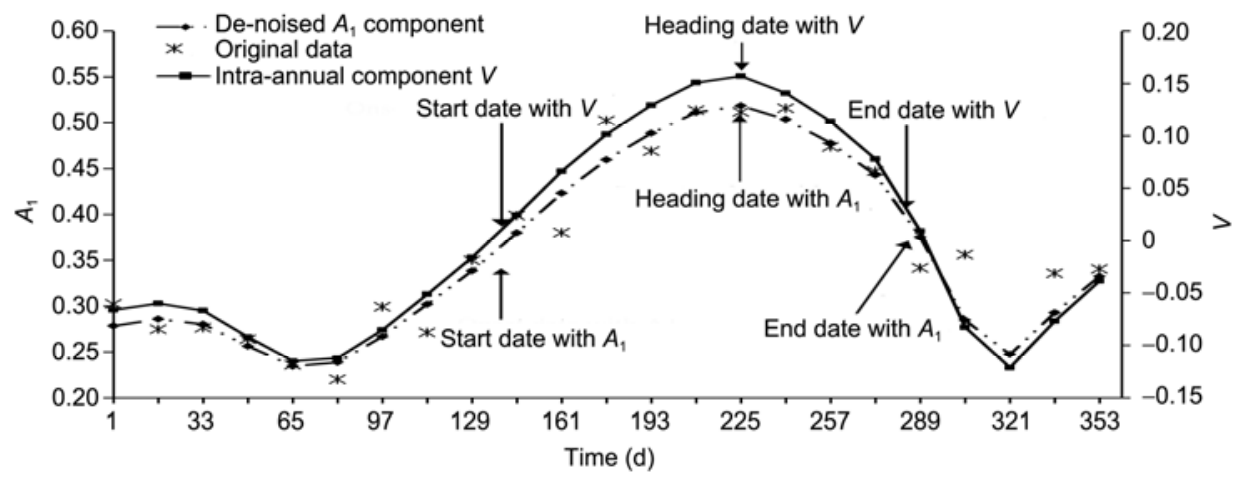

Figure 2 Original, de-noised $A_{1}$ and intra-annual component $V$ of EVI data from the Wuyi Mountain reserve area. Heading date: the date by which a certain percentage of a crop has formed seedheads, the maximum vegetation indices appears around the heading date.
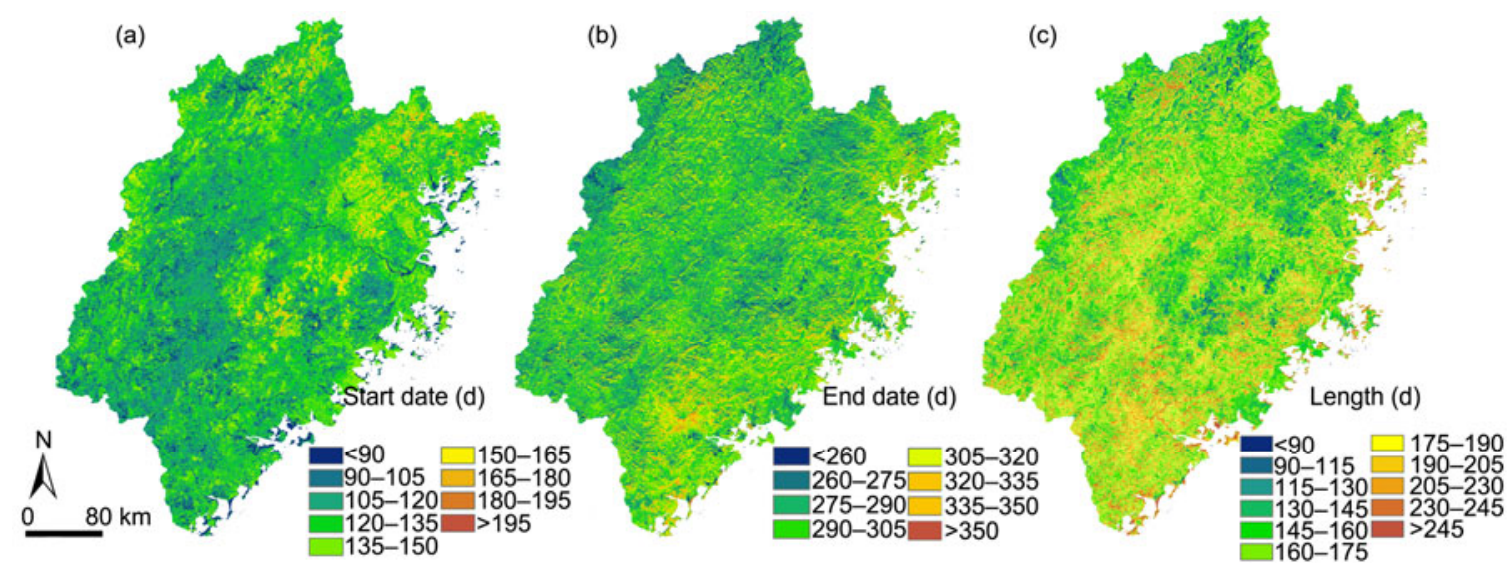

Figure 3 (Color online) Spatial distributions of average start dates (a), end dates (b), and length of growing season (c) in Fujian Province from 2001 to 2010. 

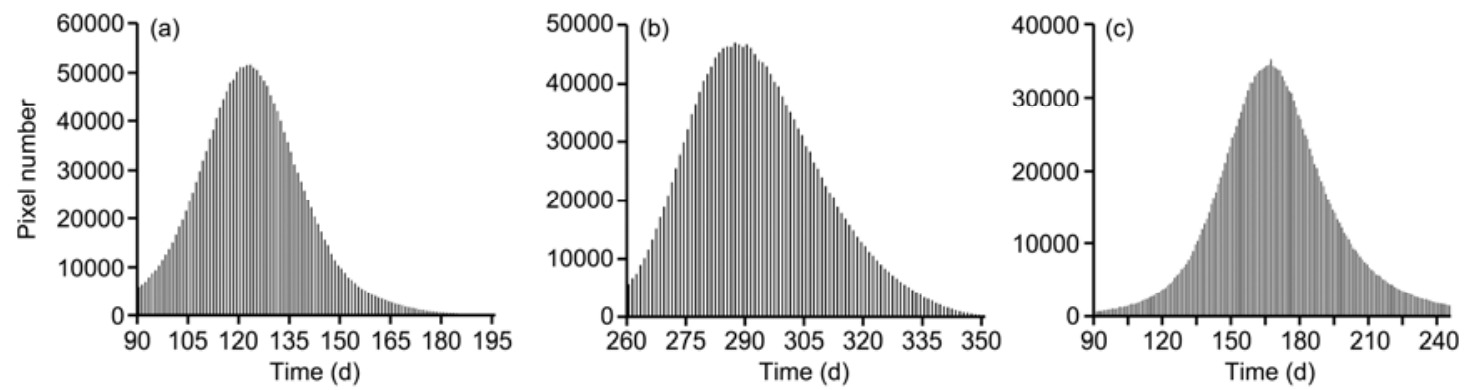

Figure 4 The histogram of average start dates (a), end dates (b), and length of growing season (c) in Fujian Province from 2001 to 2010.

altitudinal belt of above $1100 \mathrm{~m}$. The detailed reason for this is due to the combined influence of temperature and precipitation under different altitudinal belts, which could be referred to "vegetation phenology variation in relation to altitude" and the discussion session. Compared with the start dates, a much stronger negative relationship occurs between end dates, lengths of the growing season, and elevation. Along with an elevation increase of $100 \mathrm{~m}$, the end dates and length of growing season decrease approximately 1.8 and $1.9 \mathrm{~d}$ respectively. The relationships between end dates, length of growing season and elevation are shown in eq. (3) $\left(R^{2}=0.9730\right)$, eq. (4) $\left(R^{2}=0.9788\right)$ and Figure 5 respectively. The regression models can be expressed as:

$$
\begin{gathered}
S_{\text {date }}=121.61+0.01445 \times E\left(R^{2}=0.1063\right), \\
E_{\text {date }}=320.11+0.017928 \times E\left(R^{2}=0.9730, P<0.01\right), \\
L=180.39+0.019123 \times E\left(R^{2}=0.9788, P<0.01\right),
\end{gathered}
$$

where variable $S_{\text {date }}, E_{\text {date }}, L$ is the start date, end date and length of growing season respectively, and the variable $E$ is the elevation.

\subsection{Variation in vegetation phenology at regional scale}

The inter-annual variations of vegetation phenology indicated by start days, end days and length of growing period for the entire study area are illustrated in Figure 6. On the whole, no significantly consistent trend for vegetation phenology is observed in this ten year period. The trend analy- sis based on the non-parametric Sen's method [34] also indicates that most areas (85.4\% with $85 \%$ probability) in Fujian Province present non-significant trends in these ten years. However, a distinct inter-annual variation of vegetation phenology is observed during these ten years, as indicated by start dates, end dates, and length of the growing period. The start dates in 2003 are significantly earlier (114 yearday) and the year 2008 is the second earliest (119 yearday). Conversely, the start dates of 2001 and 2005 are obviously delayed when compared with normal years (126 yearday). The years 2003 and 2008 are characterized as anomalously warm, indicated by the highest minimum temperature during the spring season. The extremely high temperatures were observed and reported across Eurasia and nearly the entire country of China in 2003 [35,36].

The end dates are distinctly delayed in 2003, 2005, and 2008. The years 2005 and 2008 are characterized by a relatively high average temperature, extremely high maximum temperature (2005), or very high minimum temperature (2008) in its corresponding period (October), which indicated relatively higher effective accumulated growing degree-days. Combined analysis with average, maximum and minimum temperature is more efficient and powerful in characterization of climate conditions, since vegetation growth in subtropical areas is sensitive to the effective accumulated growing degree-days, e.g. accumulated degree-days above $10^{\circ} \mathrm{C}$. The end dates obviously occurred earlier in 2001 and 2007. With distinctly earlier start days and delayed end dates, an obviously longer growing season is observed in both 2003 and 2008, reflecting the influence of anomalously warm temperatures.
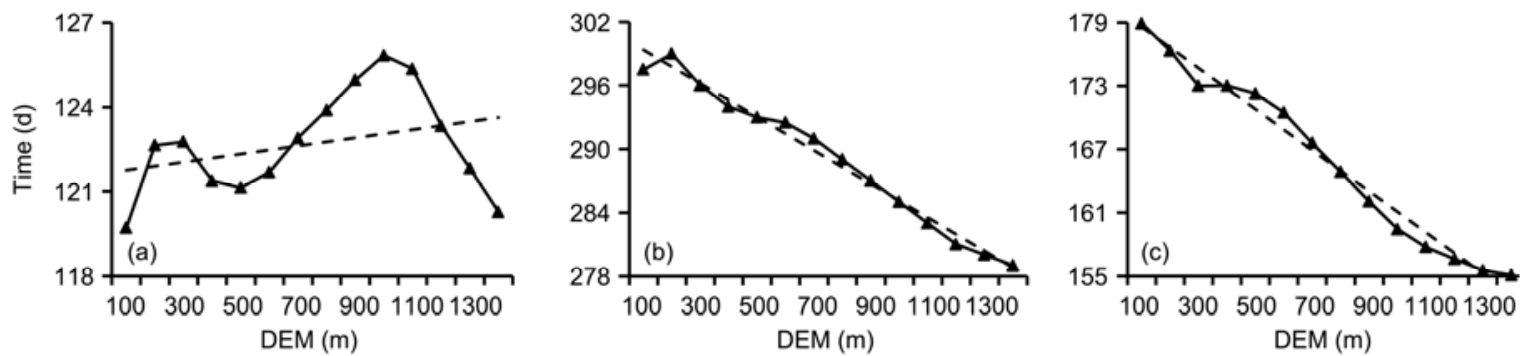

Figure 5 The relationship between elevation and onset dates (a), offset dates (b), and length of the growing season (c). 


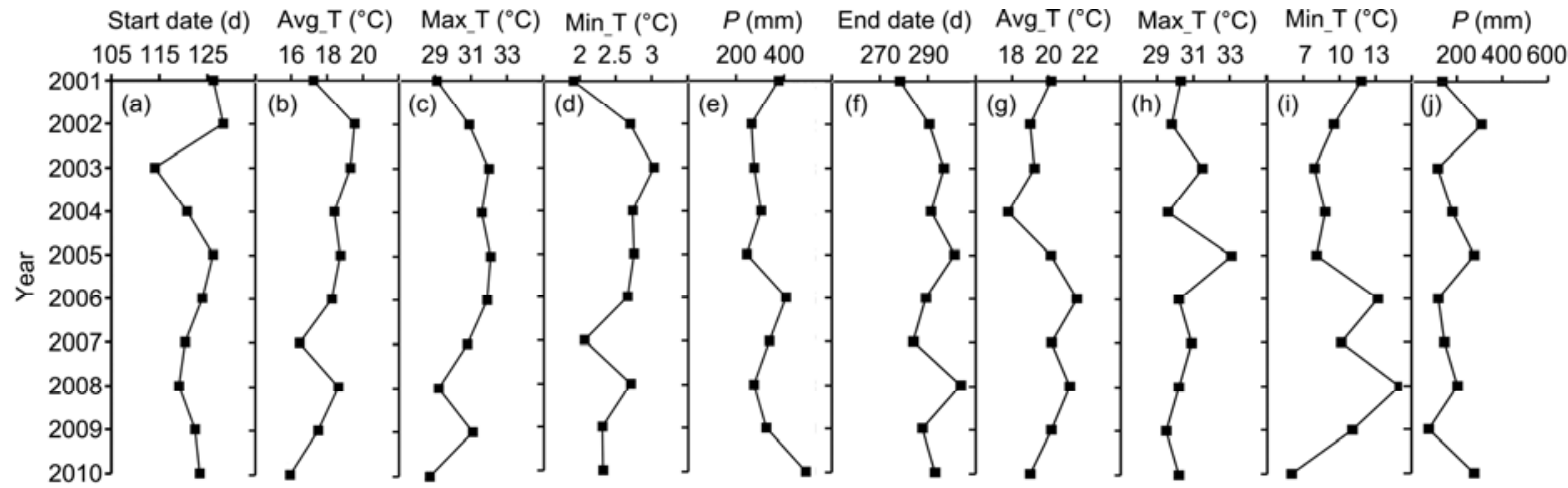

Figure 6 Inter-annual variations in average start dates (a) and corresponding average temperatures (b) (Avg_T), maximum temperatures (Max_T) (c), minimum temperatures $\left(\mathrm{Min}_{-} \mathrm{T}\right)(\mathrm{d})$ and precipitation $(P)(\mathrm{e})$, average end dates (f) and corresponding average temperatures $(\mathrm{g})$, maximum temperatures (h), minimum temperatures (i) and precipitation (j) of the whole study region during 2001-2010.

\subsection{Vegetation phenology change among different vegetation types}

The start dates, end dates and length of vegetation growth season are calculated from 2001 to 2010 among different vegetation types/land uses (Figure 7). The start dates of growing season were generally consistent among different vegetation types/land uses during the study period 2001-2010, with hardwood forest being the earliest (average: $116 \mathrm{~d}$, range: $110-120 \mathrm{~d}$ ), followed by bamboo forest (average: $123 \mathrm{~d}$, range: $116-128 \mathrm{~d}$ ) and coniferous forest (average: $120 \mathrm{~d}$, range: $116-133 \mathrm{~d}$ ). The start dates varied by around one week among these four vegetation types. Inter-annual variation of start dates also varied considerably among different types of vegetation/land use. The greatest inter-annual variation in spring green-up dates was observed from the urban regions (average: $120 \mathrm{~d}$, range: $113-138 \mathrm{~d}$ ).

Compared with inter-annual variation of start dates, the end dates of growing season are very consistent among hardwood forest, coniferous forest and bamboo forest areas. In general, the end dates of the growing season of the bam- boo forest from 2001-2010 are the earliest (average: $288 \mathrm{~d}$, range: $276-303 \mathrm{~d}$ ), followed by the hardwood forest (average: 289 d, range: $280-302$ d) and the coniferous forest (average: $281 \mathrm{~d}$, range: 280-302 d). The differences between these three vegetation types are generally less than one week. In 2008, these three kinds of forests had exactly the same end dates. With regard to the inter-annual variation, inconsistent values were also observed from the urban regions, with latest end dates in 2002 and 2008 and earliest end dates from 2004 to 2007. The length of vegetation growing season was generally consistent among different vegetation types/land uses during the study period 20012010, with hardwood forest being the longest (163-191 d), followed by bamboo forest (152-186 d) and coniferous forest (150-185 d).

The inter-annual variations of temperature and precipitation are consistent among these four vegetation types/land uses (Figure 7). The climate in the urban area is characterized by having relatively higher temperatures during both start and end dates, with less precipitation during spring

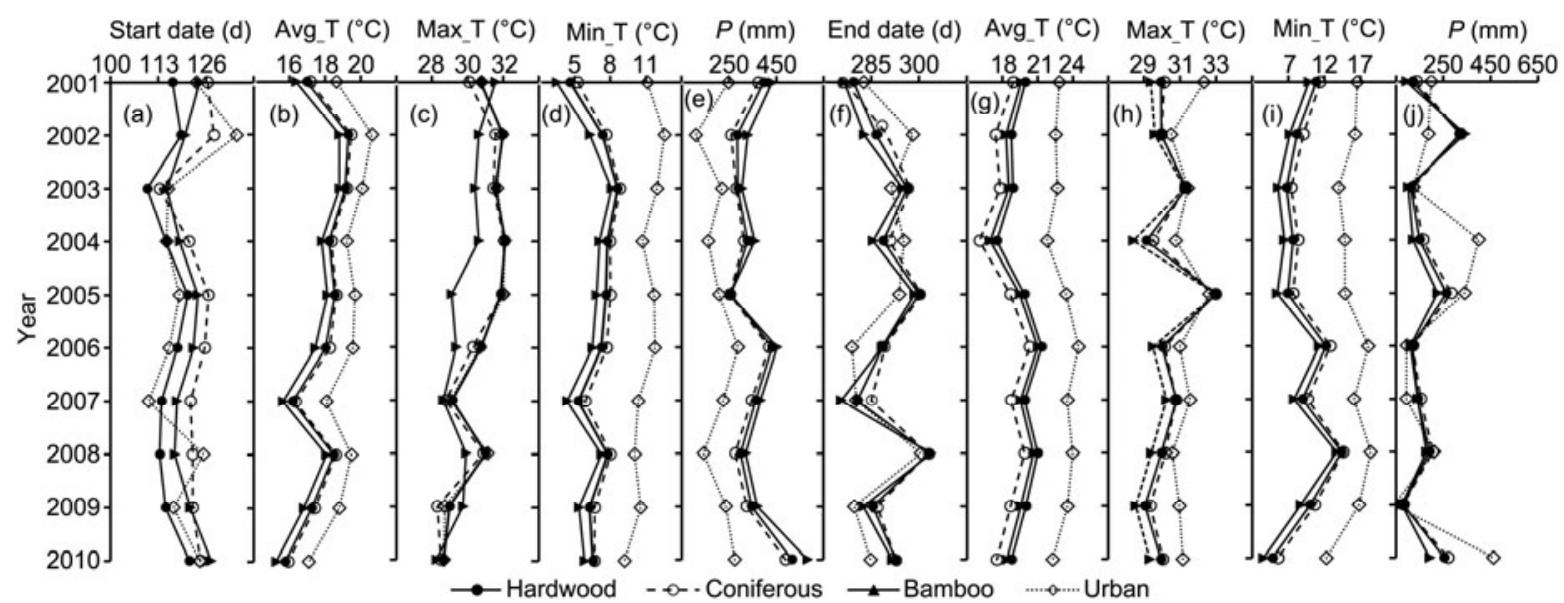

Figure 7 Inter-annual variations in average start dates (a) and corresponding average temperatures (Avg_T) (b), maximum temperatures (Max_T) (c), minimum temperatures (Min_T) (d) and precipitation $(P)(\mathrm{e})$, average end dates (f) and corresponding average temperatures $(\mathrm{g})$, maximum temperatures $(\mathrm{h})$, minimum temperatures (i) and precipitation (j) with different vegetation types during 2001-2010. 
periods but more precipitation during autumn periods. The relatively warmer climate in the urban region can partially account for the generally earlier start dates of the growing season observed in this area. However, rainfall deficiency directly leads to the delayed start dates of the urban region observed in 2002 and 2008. Minor differences of both temperature and precipitation were observed in the hardwood forest, coniferous forest and urban regions.

\subsection{Vegetation phenology variations in relation to altitude}

To examine the effects of terrain on vegetation phenology during 2001-2010 in detail, we calculated the mean values of start, end, and the length of vegetation growing period among different altitudinal belts: below 200, 200-400, 4001000, and above $1000 \mathrm{~m}$ (Figure 8). Results indicate that the start, end, and length of the vegetation growing period vary among different altitudinal gradients each year. The inter-annual variation of start dates in an altitudinal band of below $200 \mathrm{~m}$ is distinctly different from other altitudinal bands, generally with earliest start dates. However, the latest start dates in the lowest altitudinal belt less than $200 \mathrm{~m}$ occurred in 2002 and 2008. From 2001 through 2010, the earliest start dates occurred in 2003 and 2008 consistently among all altitudinal belts. However, significantly distinct variations in the start dates in the year 2010 were observed among different altitudinal bands.

We also evaluated the inter-annual variations of temperature (average, maximum, minimum) and precipitation during the start dates (April for temperature, accumulated value of March and April for precipitation) and end dates (October for temperature, accumulated value of September and October for precipitation) among different altitudinal bands from 2001 to 2010 (Figure 8). As discussed above, years 2003 and 2008 are characterized as very warm and dry. Conversely, year 2010 is characterized as relatively cold and wet. The year 2006 had ample rainfall and moderate temperatures. If we examine the altitudinal variation of precipitation during these ten years, we can find that precipitation in low altitudes (below $200 \mathrm{~m}$ ) is much less than in higher altitudes above $200 \mathrm{~m}$. However, no distinct difference in precipitation is observed within altitude belts of 200-400, 400-1000 and above $1000 \mathrm{~m}$. This indicates that the increase of precipitation with elevation is limited within relatively lower altitudinal areas.

From the above analysis, we can infer that start dates of vegetation are controlled by both temperature and precipitation, especially at low altitudes. In general, earlier start dates of vegetation growing season were observed at low altitudes during these ten years, due to the prevalence of a relatively warmer climate in these lowland areas. However, the delayed start dates of the vegetation growing season at low altitudes occurred in 2002 and 2008, as a result of rainfall deficiency. During relatively water-deficient years, there were generally little variations of start dates among different altitudinal belts. Besides, the start dates of altitudinal belts of above $1000 \mathrm{~m}$ were even earlier than lower altitudinal belts in these years, i.e. in 2008. It is obvious that consistently later start dates along with increasing altitude were only observed in water-sufficient years. Extremely abundant rainfall might exaggerate the altitudinal difference of start dates of growing season, especially during the relatively colder year. For example, in 2010, the start dates of the growing season at low altitudes are much earlier than at high altitudes.

Contrary to the inter-annual variation of start dates, the end dates of growing season are very consistent among different altitudinal bands. The end dates generally become earlier with increasing elevation, in accordance with the relatively colder temperatures at higher altitudes. Similar to the inter-annual variation of start dates, distinct inter-annual variations of end dates are also observed during the study period. Years with abundant rainfall and adequate effective accumulated temperatures resulted in obvious delayed end dates of the vegetation growing season, such as in years

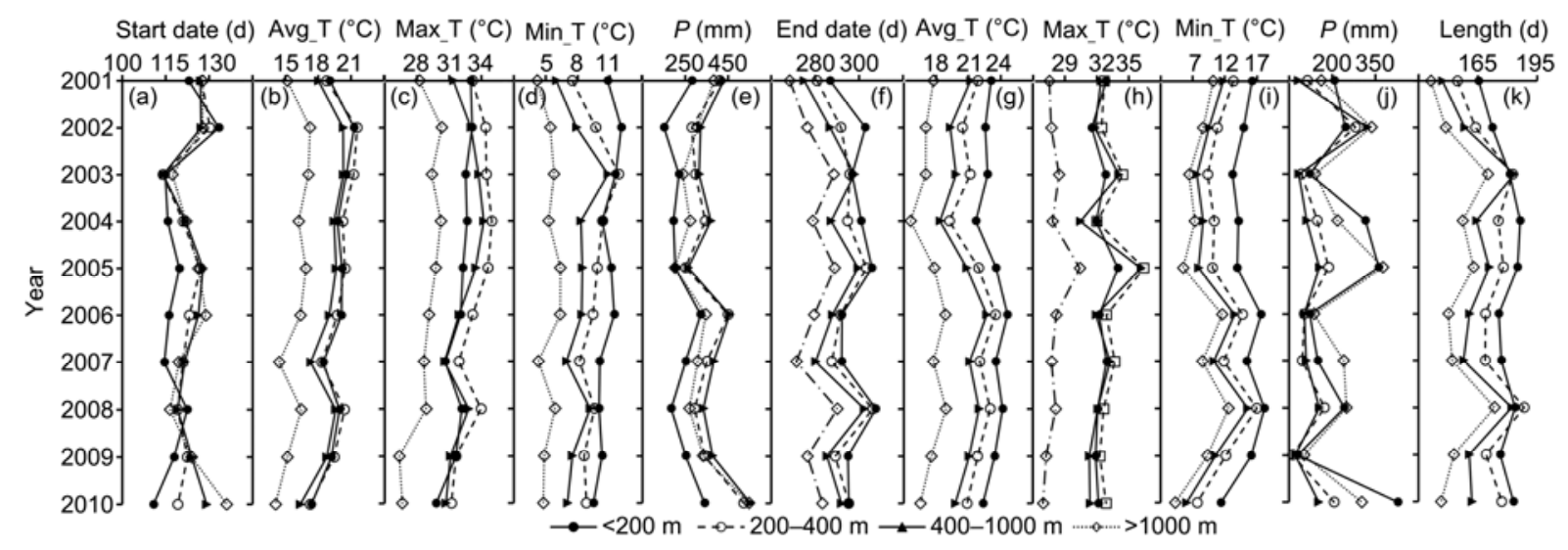

Figure 8 Inter-annual variations in average start dates (a) and corresponding average temperatures (Avg_T) (b), maximum temperatures (Max_T) (c), minimum temperatures (Min_T) $(\mathrm{d})$ and precipitation $(P)(\mathrm{e})$, average end dates (f) and corresponding average temperatures $(\mathrm{g})$, maximum temperatures $(\mathrm{h})$, minimum temperatures (i), precipitation (j) and average length (k) with different altitudinal gradients during 2001-2010. 
2005 and 2008. It appears that the end dates of the growing season are more sensitive to variations in precipitation during the corresponding period, probably due to the relatively deficit precipitation in autumn season compared to spring season. Water deficiency could directly result in the advancement of end dates, as occurring in 2001, 2007 and 2009. With generally delayed start dates and earlier end dates, the length of the growing season is generally shortened with increasing altitude.

\section{Discussions}

The relationship between vegetation phenology and temperature is a crucial topic in global change research because it indicates dynamic responses of terrestrial ecosystems to climate changes [37-39]. Siebert and Ewet [40] revealed that the spatio-temporal variability of phenology could be explained through day length corrected temperature sums, based on a comprehensive dataset (656234 phenological observations at 6019 observation sites) about the phenology of oat (Avena sativa L.) and related climate data from Germany for the period 1959-2009. Our results indicated that the start and end dates of growing season in subtropical areas are closely related to their corresponding monthly effective daily temperature sum indicated by combination of maximum, average and minimum temperatures. This finding is consistent with recent studies [40-42]. Our research further emphasized that effective daily temperature sums should better be taken into consideration instead of average temperature commonly applied in similar studies $[12,14,43]$.

On the other hand, few studies have thoroughly investigated the complex relationship between phenology and climate on different topographic conditions. Several studies illustrated that a general trend of earlier start dates, later end dates and longer growing season was observed at lower altitude areas [11,13,44,45]. However, Chang et al. [14] presented completely opposite results, possibly due to plant adaptation to lower temperature at high elevations. Elmore et al. [46] also examined that growing season length unexpectedly increases with increasing elevation at elevations below $275 \mathrm{~m}$ in mid-Atlantic, USA forests. Iversen et al. [47] assessed vegetative and flowering phenology repeatedly in five growth forms represented by 11 common vascular plant species across an altitudinal gradient of 200 to $500 \mathrm{~m}$ a.s.l. and among differing slope aspects, and concluded that altitudes and aspects were poor predictors of phenological variations. Crimmins et al. [18] found that lower-elevation plants and high-elevation plants might exhibit delayed or advanced spring flowering due to precipitation and temperature change respectively, based on a 20year dataset collected in semiarid ecosystem across a $1200 \mathrm{~m}$ elevation gradient. Our research further improves the knowledge of the complex relationship between altitude and phenology in subtropical mountain and hill region. Our findings reveal that this altitudinal phenology relationship also depends on the inter-annual spatio-temporal variability of temperature and precipitation. We found that the positive relationship between start date and altitude occurs only during normal years with no obvious climate change; however, generally later start dates might be observed at lower altitude in relatively rainfall deficit years, corresponding to the relatively abundant precipitation at higher altitude, and no obvious difference of start dates of growing season might be observed along altitudinal gradient during extremely hot years. Therefore, overall only slightly positive correlation was observed between start dates of growing season and altitude during the whole study period.

Besides, in subtropical mountainous and hilly region, the inter-annual variation of vegetation phenology among different vegetation types could not be explained by either temperature or precipitation changes alone, as it may be affected by the characteristics of the vegetation growth cycle. For example, compared with a coniferous forest, hardwood forests grow more rapidly under similar climate conditions. A bamboo needs to produce bamboo shoots from the earth before it begins to sprout.

Knowledge on the seasonal behavior of the subtropical forest is crucial to the understanding and monitoring of its ecosystems functioning in the context of global warming. Findings in this study have complicated implications. The dynamic trend of vegetation phenology in subtropical mountain and hill region along the altitudinal gradient might be blurry as a result of global warming. We should reconsider the relationship between phenology and altitude through thoroughly accounting the deficit factors, i.e. the precipitation. Besides, with earlier start dates and later end dates in relative warm years, much longer length of growing season was obtained, especially in relatively higher altitude belts. It might imply that vegetation in relatively higher altitude is more sensible to global change, which should be better investigated for further studies.

The phenology detection method based on wavelet transform consists of three procedures: (i) establishing the NDVI/EVI time series database; (ii) decomposing the original data into different time series of multiple levels to derive intra-annual component $\mathrm{V}$; and (iii) specifying the phenological stages from the intra-annual component time series. As vegetation calendars are not available in many regions, this method has potential applicability to other regions. However, the mother wavelets used and threshold for determination of phenological stages will depend on the climate zones and also the time-interval of original NDVI/ EVI time series applied. Meyer orthogonal discrete wavelet has been shown to be powerful in the characterization of inter- annual and intra-annual vegetation variability based on a 16-d composite MODIS EVI time series, which has also been confirmed by other related studies [28-31].

Detailed ground validation was not possible as this would require a properly resourced province-scale network, 
which is fairly difficult in a mountain and hill region. Reference studies provided the most useful source of information for validation. However, it was difficult to extract the correct dates of leaf flushing and leaf fall from the linguistic descriptions (such as the spring season, early dry period, and post-monsoon period) [13]. Further research is needed to more adequately evaluate the start and end dates of vegetation growing period [48] and there are still complications associated with the reflectance and calibration of satellite data [12].

Considerable potential exists in incorporating other ecoclimatological factors into the study, which could further account for spatio-temporal variability in vegetation phenology in this region. Additional research is needed to model such relationship in different geographic conditions to test the consistency of the results. Further studies could extend the conclusions drawn from subtropical mountain and hill region at local or regional scale to other regions such as subtropical plain areas and temperate regions at a variety of spatial scales. Moreover, since the mixed pixel effect and topography may affect the spectral characteristics in satellite image, topographically-corrected EVI might be better in exploring the climate-phenology relationship in mountain and hill region. Thus further improved knowledge of climate-phenology relationship based on different geographic regions and less disturbed NDVI/EVI database might provide great insight into understanding vegetation phenology sensitivity to global climate change in the context of topographic and plant species complexity.

\section{Conclusions}

In subtropical mountainous and hilly Fujian, the spatial pattern and inter-annual variation of vegetation phenology closely depends on both topographical and climate factors from 2001-2010. Across the whole region, start dates are generally delayed, end dates advanced, and lengths of the growing period are reduced with increasing elevations. Dynamic analysis of different altitudinal bands during 2001-2010 also indicates that the positive relationship between altitude and start dates highly depends on the combined effects of temperature and precipitation conditions during the study year. A strong positive relationship is observed in several years with extremely abundant rainfall and lower temperatures, in accordance with decreasing temperature at higher altitudes; conversely, the opposite relationship could be examined in rainfall deficient years, in accordance with increasing rainfall with altitude. In contrast to start dates, the end dates of the growing season are more sensitive to variations in precipitation during its corresponding period.

Although the trend analysis based on the non-parametric Sen's method indicates that over $80 \%$ of the area present non-significant trends during the study period (2001-2010), distinct inter-annual variations of vegetation phenology were observed during these ten years. The start dates are considerably early and end dates delayed in 2003 and 2008, resulting in an extended length of the growing period, in accordance with anomalously warm conditions. Distinct inter-annual variations of vegetation phenology are observed among different vegetation types during 2001-2010, which could not be directly explained by inter-annual variation of temperature and precipitation, reflecting the characteristics of vegetation types and growth cycles. The hardwood forest is generally characterized as having the earliest start dates and latest end dates, resulting in an extended length of the growing period. The earliest end date is generally observed in the bamboo forest. Compared with forest vegetation, inconsistent inter-annual variations of start and end dates were found in the urban region, which are inconsistent with the inter-annual climate variations, thus reflecting anthropogenic influence.

The authors thank Zhang Chungui with Fujian Meteorological Research Institute, China, for processing the climate dataset. This work was supported by the National Natural Science Foundation of China (41071267), the Scientific Research Foundation for Returned Scholars, Ministry of Education of China (2012940) and Science Foundation of Fujian Province (2012J01167 and 201210005).

1 Horion S, Cornet Y, Erpicum M, et al. Studying interactions between climate variability and vegetation dynamic using a phenology based approach. Int J Appl Earth Obs Geoinf, 2013, 20: 20-32

2 Allen C D, Breshears D D. Drought-induced shift of a forest-woodland ecotone: rapid landscape response to climate variation. Proc Natl Acda Sci USA, 1998, 95: 14839

3 Wang H L, Gan Y T, Wang R Y, et al. Phenological trends in winter wheat and spring cotton in response to climate changes in northwest China. Agric For Meteorol, 2008, 148: 1242-1251

4 Pennec A, Gond V, Sabatier D. Tropical forest phenology in French Guiana from MODIS time series. Remote Sens Lett, 2011, 2: 337-345

5 Julien Y, Sobrino J A. Global land surface phenology trends from GIMMS database. Int J Remote Sens, 2009, 30: 3495-3513

6 Ding M J, Zhang Y L, Sun X M, et al. Spatiotemporal variation in alpine grassland phenology in the Qinghai-Tibetan Plateau from 1999 to 2009. Chin Sci Bull, 2013, 58: 396-405

7 Chen X Q, Hu B, Yu R. Spatial and temporal variation of phenological growing season and climate change impacts in temperate eastern China. Glob Change Biol, 2005, 11: 1118-1130

8 Busetto L, Colombo R, Migliavacca M, et al. Remote sensing of larch phenological cycle and analysis of relationships with climate in the Alpine region. Glob Change Biol, 2010, 16: 2504-2517

9 Jeong S J, Ho C H, Gim H J, et al. Phenology shifts at start vs. end of growing season in temperate vegetation over the Northern Hemisphere for the period 1982-2008. Glob Change Biol, 2011, 17: 2385-2399

10 Bradley B A, Jacob R W, Hermance J F, et al. A curve fitting procedure to derive inter-annual phenologies from time series of noisy satellite NDVI data. Remote Sens Environ, 2007, 106: 137-145

11 Sobrino J A, Julien Y, Morales L. Changes in vegetation spring dates in the second half of the twentieth century. Int J Remote Sens, 2011, 32: 5247-5265

12 Ivits E, Cherlet M, Toth G, et al. Combining satellite derived phenology with climate data for climate change impact assessment. Glob Planet Change, 2012, 85-86: 85-97

13 Jeganathan C, Dash J, Atkinson P M. Mapping the phenology of natural vegetation in India using a remote sensing-derived chlorophyll index. Int J Remote Sens, 2011, 31: 5777-5796

14 Chang C T, Lin T C, Wang S F, et al. Assessing growing season be- 
ginning and end dates and their relation to climate in Taiwan using satellite data. Int J Remote Sens, 2011, 32: 5035-5058

15 Kramer K, Leinonen I, Loustau D. The importance of phenology for the evaluation of impact of climate change on growth of boreal, temperate and Mediterranean forests ecosystems: An overview. Int J Biometeorol, 2000, 44: 67-75

16 Penuelas J, Rutishauser T, Filella I. Phenology feedbacks on climate change. Science, 2009, 324: 887-888

17 Jentsch A, Kreyling J, Boettcher-Treschkow J, et al. Beyond gradual warming: extreme weather events alter flower phenology of European grassland and heath species. Glob Change Biol, 2009, 15: 837-849

18 Crimmins T M, Crimmins M A, David B C. Complex responses to climate drivers in onset of spring flowering across a semiarid elevation gradient. J Eeol, 2010, 98: 1042-1051

19 Jenerette G D, Scott R L, Huete A R. Functional differences between summer and winter season rain assessed with MODIS-derived phenology in a semi-arid region. J Veg Sci, 2010, 21: 16-30

20 Lloyd A H, Bunn A G, Berner L. A latitudinal gradient in tree growth response to climate warming in the Siberian taiga. Glob Change Biol, 2011, 17: 1935-1945

21 Lu S J. Fujian Climate (in Chinese). Beijing: China Meteorological Press, 1999. 45-54

22 Gao Z W. Research on Forest Resource Management (in Chinese). Fuzhou: The Cartographic Publisher of Fujian, 2004. 372

23 The People's Government of Fujian. Fujian Yearbook (in Chinese). Fuzhou: The People's Publisher of Fujian, 2010

24 Justice C O, Vermote E, Townshend J R G, et al. The Moderate Resolution Imaging Spectroradiometer (MODIS): Land remote sensing for global change research. IEEE Trans Geosci Remote Sens, 1998, 36: 1228-1249

25 Waring R H, Coops N C, Fan W, et al. MODIS enhanced vegetation index predicts tree species richness across forested ecoregions in the contiguous USA. Remote Sens Environ, 2006, 103: 218-226

26 Sakamoto T, Yokozawa M, Toritani H, et al. A crop phenology detection method using time-series MODIS data. Remote Sens Environ, 2005, 96: 366-374

27 Galford G L, Mustard J F, Melillo J, et al. Wavelet analysis of MODIS time series to detect expansion and intensification of rowcrop agriculture in Brazil. Remote Sens Environ, 2008, 112: 576-587

28 Setiawan Y D, Yoshino K, Philpot W D. Characterizing temporal vegetation dynamics of land use in regional scale of Java Island, Indonesia. J Land Use Sci, 2011: 1-30

29 Alados C L, Puigdefábregas, Martínez-Fernández J. Ecological and socio-economical thresholds of land and plant-community degradation in semi-arid Mediterranean areas of southeastern Spain. J Arid Environ, 2011, 75: 1368-1376

30 Martínez B, Gilabert M A. Vegetation dynamics from NDVI time series analysis using the wavelet transform. Remote Sens Environ, 2009, 113: 1823-1842
31 Singh A, Dutta R, Stein A, et al. A wavelet-based approach for monitoring plantation crops (tea: Camellia sinensis) in North East India. Int J Remote Sens, 2012, 33: 4982-5008

32 White M A, Thornton P E, Running S W. A continental phenology model for monitoring vegetation responses to interannual climatic variability. Glob Biogeochem Cycles, 1997, 11: 217-234

33 Fisher J I, Mustard J F, Vadeboncoeur M A. Green leaf phenology at Landsat resolution: Scaling from the field to the satellite. Remote Sens Environ, 2006, 100: 265-279

34 Sen P K. Estimates of the regression coefficient based on Kendall's tau. J Am Stat Assoc, 1968, 324: 1379-1389

35 Japan Meteorological Agency. Annual Report on the Climate System 2008. 2008

36 Zhang F, Gao H, Cui X. Frequency of extreme high temperature days in China, 1961-2003. Weather, 2008, 2: 46-49

37 Walther G R, Post E, Convey P, et al. Ecological responses to recent climate change. Nature, 2002, 416: 389-395

38 Menzel A, Sparks T H, Estrella N, et al. European phenological response to climate change matches the warming pattern. Glob Change Biol, 2006, 12: 1969-1976

39 Cleland E E, Chuine I, Menzel A, et al. Shifting plant phenology in response to global change. Trends Ecol Evol, 2007, 22: 357-365

40 Siebert S, Ewert F. Spatiotemporal patterns of phenological development in Germany in relation to temperature and day length. Agric For Meteorol, 2011, 152: 44-57

41 Dinis L T, Peixoto F, Pinto T, et al. Study of morphological and phenological diversity in chestnut trees ("Judia" variety) as a function of temperature sum. Environ Exp Bot, 2011, 70: 110-120

42 Van Oort P A J, Zhang T Y, de Vries M E, et al. Correlation between temperature and phenology prediction error in rice (Oryza sativa L.). Agric For Meteorol, 2011, 151: 1545-1555

43 Piao S L, Fang J Y, Zhou L M, et al. Variations in satellite-derived phenology in China's temperate vegetation. Glob Change Biol, 2006, 12: $672-685$

44 Zhang X, Friedl M A, Schaaf C B, et al. Climate controls on vegetation phenological patterns in northern mid- and high latitudes inferred from MODIS data. Glob Change Biol, 2004, 10: 1133-1145

45 Piao S L, Cui M D, Chen A P, et al. Altitude and temperature dependence of change in the spring vegetation green-up date from 1982 to 2006 in the Qinghai-Xizang Plateau. Agric For Meteorol, 2012, 151: 1599-1608

46 Elmore A J, Guinn S M, Minsley B J, et al. Landscape controls on the timing of spring, autumn, and growing season length in mid-Atlantic forests. Glob Change Biol, 2012, 18: 656-674

47 Iversen M, Bråthen K A, Yoccoz Nigel G, et al. Predictors of plant phenology in a diverse high-latitude alpine landscape: Growth forms and topography. J Veg Sci, 2009, 20: 903-915

48 Beurs K M, Henebry G M. Phenological Research. Dordrecht: Springer Netherlands, 2010. 177-208

Open Access This article is distributed under the terms of the Creative Commons Attribution License which permits any use, distribution, and reproduction in any medium, provided the original author(s) and source are credited. 